\title{
¡No creo en lo que dicen! Pero defenderé su derecho a decirlo. Una reflexión sobre la importancia constitucional y para los derechos humanos de la libertad de expresión*
}

\author{
I Don't Believe in What They Say! But I Will Defend their Right to Say it. A Reflection on the Constitutional and \\ Human Rights Importance of Freedom of Expression
}

\author{
Francisco José Chaux Donado a 1 \\ Práctica privada, Colombia \\ fjchaux@gmail.com \\ ORCID: http://orcid.org/0000-0002-1030-410X
}

DOI: https://doi.org/10.11144/Javeriana.vj139.ncel

Recepción: 24 Mayo 2019

Aceptación: 29 Agosto 2019

Fecha de publicación: 30 Diciembre 2019

\section{Resumen:}

La libertad de expresión es uno de derechos más importantes y un elemento estructural de la democracia constitucional moderna. A través de él se protege y garantiza el intercambio de ideas, la deliberación política y la generación de consensos para la vida en sociedad. Se trata de la garantía de poder formular nuestros propios argumentos, de decir, lo que pensamos y de gozar de libertad para dar opiniones y comunicarlas. Todos los medios de comunicación se reducirían a un simple instrumento de propaganda sin la libertad de expresión. Incluso, una multiplicidad de derechos se reduciría a la nada sin la posibilidad de un dialogo libre, sincero y autónomo. Este artículo es un intento por exponer la calidad fundamental de la libertad de expresión para el derecho constitucional occidental y para el derecho internacional de los derechos humanos. La parte inicial se encarga del fundamento e importancia de la libertad de expresión, para luego exponer sus efectos prácticos. Finalmente, se plantea una conclusión donde se postula que al ser la libertad de expresión un derecho humano, esta debe entenderse siguiendo el método de interpretación moral.

Palabras clave: libertad de expresión, derecho humano, derecho constitucional, democracia, verdad, información, límite.

\section{Abstract:}

Freedom of expression is one of the most important rights and a structural element of modern constitutional democracy. Through it, the exchange of ideas, political deliberation and the generation of consensus for life in society are protected and guaranteed. It is about the guarantee of being able to formulate our own arguments, of saying what we think and of enjoying the freedom to give opinions and communicate them. All the media would be reduced to a simple propaganda instrument without freedom of expression. Even a multiplicity of rights would be reduced to nothing without the possibility of free, sincere and autonomous dialogue. This article is an attempt to expose the fundamental quality of freedom of expression for Western constitutional law and international human rights law. The first part deals with the philosophical foundations and importance of freedom of expression, and the second part exposes the practical effects of the right. Finally, a conclusion is made, where it is postulated that since freedom of expression is a human right, it must be understood following the moral method of interpretation.

Keywords: freedom of expression, human right, constitutional law, democracy, truth, information, limits.

"La libertad de expresión es la base de los derechos humanos, la raiz de la naturaleza humana y la madre de la verdad. Matar la libertad de expresión es insultar a los derechos humanos, sofocar la naturaleza humana y suprimir la verdad".

Liu Xiaobo

Notas de autor

1 Viceministerio de Relaciones Políticas - República de Colombia

a Autor de correspondencia. Correo electrónico: fjchaux@gmail.com 


\section{Introducción}

Quinientos años antes de Cristo, en un pequeño pueblo al occidente del mundo conocido, surgió una idea novedosa. Algo había despertado para influenciar el pensamiento de las personas, una idea que ni el paso del tiempo o los cambios que trae la acumulación de los siglos sería capaz de eliminar. Fue en Atenas donde el primer ciudadano libre de una democracia expresó su opinión sin miedo a la persecución de un tirano ${ }^{[1]}$.

El derecho a la libertad de expresión surgió del mar cristalino del pensamiento libre, pero no siempre se ha gozado de libertad por parte de las personas; el pensamiento crítico, la diferencia y la autonomía invariablemente han tenido y tendrán sus detractores. ${ }^{\left[{ }^{[2]}\right.}$ El precio de la libertad ha sido la vigilancia eterna frente a los intentos — sutiles o burdos- de la tiranía por disminuir su voz ${ }^{[3]}$.

Mientras el lector se encuentra con estas palabras, lo hace en un país libre ${ }^{[4]}$, una república de leyes, un Estado que no erige barreras para la expresión del pensamiento o la búsqueda del conocimiento. Donde la verdad se valora por encima de todas. Esa verdad que da perspectiva, que despeja la realidad y calma las pasiones, que muestra a la intolerancia y al odio en su mejor versión: de mentira y falsedad.

El verdadero equilibrio democrático se encuentra en el libre intercambio de ideas. El mejor examen de la verdad es el poder del pensamiento para ser aceptado en la competencia del libre mercado que lleva implícito la libertad de expresión ${ }^{[5]}$.

Hoy vemos la libertad de expresión como un derecho humano reconocido por una pluralidad de instrumentos, entre ellos la Declaración de Derechos del Hombre y del Ciudadano, la Declaración Universal de Derechos Humanos, el Pacto Internacional de Derechos Civiles y Políticos, la Declaración Americana de Derechos y Deberes del Hombre y en la Convención Americana de Derechos Humanos, por mencionar $\operatorname{algunos}^{[6]}$.

Sin embargo, esta línea de protección de la libertad de expresión no es exclusiva del derecho internacional de los derechos humanos, también desde el constitucionalismo occidental — disciplina fundante de los derechos humanos - se dieron los primeros pasos para la protección de esta garantía.

En efecto, la Declaración de Derechos de Virginia de $1776^{[7]}$, puede ser considerada como el primer compromiso constitucional moderno que garantiza el derecho a la libertad de expresión ${ }^{[8]}$. Sobre este derecho, Edmund Randolph, miembro del comité redactor de la declaración, dijo que esta garantía es el fruto de una democracia genuina ${ }^{[9]}$. Esta metáfora orgánica es, sin duda, correcta, pero más de dos siglos después el fruto aún está madurando ${ }^{[10]}$.

Como legítima democracia constitucional, la Constitución de 1991 establece en su artículo 20 la garantía de toda persona para expresar y difundir libremente su pensamiento y opinión. Sin embargo, esta redacción genérica del derecho a la libertad de expresión, es solo el primer escalón de este derecho fundamental, en otras palabras, la semilla que se establece en el artículo 20 permite diversos frutos, diversas formas de entender ese elemento angular de la democracia ${ }^{[11]}$.

Lo anterior reconoce que la libertad de expresión no es solo un derecho fundamental, se trata de un principio de la más alta jerarquía ${ }^{[12]}$ que requiere y demanda de una interpretación para su aplicación ${ }^{[13]}$, de una adaptación a la realidad ${ }^{[14]}$.

En este artículo se muestran los diversos alcances y entendimientos que la libertad de expresión ha recibido en occidente. Para lograr lo anterior, se empezará por (1) el fundamento e importancia de la libertad de expresión, (2) los efectos prácticos de la libertad de expresión y (3) una conclusión donde se postula que al ser la libertad de expresión un derecho humano, esta debe interpretarse de manera moral. 


\section{El fundamento e importancia de la libertad de expresión}

La estructura básica del derecho a la libertad de expresión consiste en la garantía para cada individuo de recibir y buscar información e ideas de todo tipo y por cualquier método, así como a decir su opinión a través del instrumento de comunicación de su elección ${ }^{[15]}$. Cualquier medio de comunicación, bien sea escrito, radial, televisivo o una red social, puede ser utilizado para difundir una opinión, pensamiento o idea: "el derecho a la libertad de expresión, no puede ejercitarse en el vacío" ${ }^{[16]}$.

Desde la otra cara de la moneda, la libertad de expresión incluye la posibilidad de abstenerse de expresar una opinión o a negarse a compartirla con los demás ${ }^{[17]}$. En efecto, la libertad de expresión prohíbe forzar a las personas a traicionar sus convicciones. La coerción sobre cualquier ser humano para que apoye ideas $o$ acciones que considera objetables será siempre degradante y contrario a la libertad ${ }^{[18]}$. Como bien diría Thomas Jefferson "obligar a una persona a apoyar una opinión de la cual descree o aborrece, es pecaminoso y tiránico" ${ }^{[19]}$.

Ahora, la libertad de expresión no es absoluta, esta puede ser restringida por razones de seguridad nacional, privacidad, reputación o incluso el contenido mismo del discurso se restringe cuando hace un llamado a la violencia o intolerancia, lo que la doctrina estadounidense denomina hate speech.

Frente a los límites a la libertad de expresión, la jurisprudencia Interamericana ha concluido que estas barreras deben encontrarse establecidas

"de forma previa y de manera expresa, taxativa, precisa y clara en una ley, tanto en el sentido formal como material. Lo anterior significa que el texto de la ley debe establecer en forma diáfana las causales de responsabilidad posterior a las que puede estar sujeto el ejercicio de la libertad de expresión" ${ }^{20]}$.

De manera universal se ha reconocido que es válido limitar expresiones que: (1) hacen propaganda a favor de la guerra; (2) realizan un discurso de odio, discriminatorio, de apología al delito o a la violencia; (3) la pornografía infantil y (4) la incitación directa y pública a cometer genocidio ${ }^{[21]}$.

No obstante, ningún límite puede llegar a eliminar la libertad de expresión, si existe una estrella fija en la constelación constitucional occidental, es que ningún agente del Estado, sin importar su jerarquía, puede decidir lo que es aceptable en asuntos de opinión como lo es la política, el nacionalismo, la religión o el fútbol ${ }^{[22]}$.

El derecho a la libertad de expresión, es un derecho humano nuclear de las personas, por lo cual genera una obligación para el Estado de respeto, protección y realización ${ }^{[23]}$. Se trata de una garantía que incluso se extiende a la relación entre los particulares y a sus acuerdos o contratos ${ }^{[24]}$.

Vale decir que la libertad de expresión es un derecho compuesto o interconectado ${ }^{[25]}$, que es interdependiente e interrelacionado con otros derechos ${ }^{[26]}$; lo que Jürgen Habermas denomina la cooriginalidad de los derechos. ${ }^{[27]}$ Esta "cooriginalidad" de la libertad de expresión se presenta de manera evidente con derechos como la libertad de conciencia, la libertad de pensamiento y con la habilidad de ejercer autonomía política por parte del individuo ${ }^{[28]}$.

Lo anterior significa que la libertad de expresión se sitúa en el mismo plano jerárquico que otros derechos humanos como la vida o la igualdad, y su existencia es necesaria para el ejercicio de otros derechos.

La libertad de expresión hace parte de los "derechos fundacionales cuya realización es esencial para el disfrute y la protección de todos los derechos humanos" ${ }^{\text {[29] }}$. En términos de la CIDH, es un derecho que define

"nuestra naturaleza humana, como hombres y mujeres provistos de pensamiento, dignidad y autonomía. En efecto, sin este derecho no podrían proyectarse en el mundo ni realizarse algunos de los componentes más esenciales de la persona libre y racional". ${ }^{[30]}$ 
Es decir que la "carencia de libertad de expresión es una causa que contribuye al irrespeto de los otros derechos humanos".[31]

La libertad de expresión responde a la creencia que el intercambio libre de opiniones, así como la discusión sin temor por parte de los ciudadanos, es el punto de partida para la moderna democracia constitucional. La realización del gobierno "del pueblo, por el pueblo y para el pueblo" ${ }^{[32]}$, no se alcanza a través del miedo y la represión de quien manifiesta su pensamiento, el camino hacia la verdadera democracia se encuentra en las oportunidades para discutir de manera libre las ideas y las opiniones ${ }^{[33]}$. Jamás una sociedad democrática podrá desestimular el pensamiento y las opiniones, la imaginación de sus ciudadanos para discutir un ordenamiento jurídico y político, que responda de manera más fiel a sus intereses ${ }^{[34]}$.

Lo anterior reconoce - la obviedad-que los seres humanos tenemos opiniones diversas y diferentes, en especial sobre asuntos políticos, jurídicos y sociales. Esta obviedad se traduce en una noción general del derecho en occidente, según la cual nadie puede ser obligado a opinar de cierta manera, ser castigado, sufrir perjuicio, discriminación o represión por pensar diferente a la mayoría y expresar esa opinión ${ }^{[35]}$.

En efecto, la libertad de expresión protege 4 valores subyacentes: (A) asegura la realización personal del individuo, (B) promueve el descubrimiento de la verdad, (C) garantiza la participación de todos los miembros de la sociedad en la toma de decisiones y (D) impulsa la estabilidad social a través de la discusión y la solución de las diferencias ${ }^{[36]}$.

La importancia de la libertad de expresión para la democracia constitucional no puede dejar de reafirmarse, este derecho es el escudo del proceso comunicativo que permite el intercambio de ideas, que es la base fundamental de este tipo de gobierno ${ }^{[37]}$. De hecho, resulta difícil encontrar un derecho que sea más importante para una sociedad democrática que la libertad de expresión. Si no existe la posibilidad de decir nuevas ideas, de expresar opiniones sobre el funcionamiento de las instituciones públicas - esto es el discurso libre y sin inhibiciones-, no existirá una verdadera democracia ${ }^{[38]}$.

Es una desventaja para cualquier democracia constitucional y una consecuencia antiliberal para los derechos humanos el censurar ideas por callar al emisor, o al concluir el juez que el discurso debe ser silenciado por no compartir las formas. Esto no es "nada diferente a la eliminación de la comunicación libre, derecho angular para la Democracia" ${ }^{[39]}$.

Toda decisión judicial, donde se interprete el uso de la libertad de expresión y pueda limitarse la opinión de un individuo, no puede olvidar que la libertad de expresión, sin importar las formas del discurso, asegura la libre, autónoma e independiente formación de la opinión pública. Dicha opinión pública determina la composición de los órganos representativos y las preferencias de las personas frente a las ideas políticas y los asuntos sociales en una democracia constitucional.

La libertad de expresión se concreta en el voto libre de los ciudadanos. Esta es la única garantía para evitar que la superstición, las mentiras o los mitos se adueñen de la voluntad política de las personas, que hacen que demagogos e hipócritas ganen las elecciones, que es el primer paso para transformar la democracia en una dictadura sangrienta. ${ }^{[40]}$

Ahora, debemos preguntarnos ¿la esfera de protección de la libertad de expresión incluye las opiniones que son contrarias a las buenas costumbres, sensibilidad o a la moralidad de algunos?

$\mathrm{Al}$ enfrentarse con este interrogante, la Corte Suprema de los Estados Unidos, en el caso New York Times vs. Sullivan, estableció que no existía fundamento jurídico para conceder la protección solicitada por un funcionario estatal, en razón a la publicación de un aviso donde era acusado de realizar un tratamiento fuerte y excesivo, a unos manifestantes de los derechos civiles.

La Corte negó la protección constitucional y revocó el pronunciamiento de instancia que había otorgado una indemnización al servidor público demandante, en razón a que la crítica —en sus diversas formas - a la labor de los servidores públicos es una garantía fundamental de la democracia constitucional, y establecer una restricción sobre el contenido de lo que puede ser expresado llevaría a concluir que ciertas opiniones pueden 
ser expresadas y otras no. "La crítica a la conducta oficial no pierde su protección constitucional por el mero hecho de ser efectivamente una crítica" ${ }^{\text {"41] }}$

La misma Corte Suprema de los Estados Unidos, ha reconocido la existencia de una garantía constitucional para expresar opiniones y frases fuertes, incluso contrarias a las buenas costumbres. Al respecto, tres pronunciamientos resultas reveladores: (1) la Sentencia de Cohen vs. California (1971), (2)FCC vs. Pacifica Foundation (1978) y (3) la Sentencia Hustler Magazine, Inc. vs. Falwell (1988). ${ }^{[42]}$

En los casos referidos, la Corte determinó que la libertad de expresión establece un amplio margen de protección tan extenso, que protege lo que es artístico para algunos, mientras que es considerado vulgar o de poco gusto para otros. El discurso protegido por la libertad de expresión no pierde su amparo por el hecho de sonrojar, avergonzar u ofender la moral o costumbres de algunos.

Lo anterior no es novedoso para el derecho constitucional occidental, bien diría John Stuart Mill que el juicio ilustrado sólo es posible si se consideran todos los hechos e ideas sin importar su fuente, toda vez que esto permite comprobar las propias conclusiones. "Por tanto, todo punto de vista aun los que son "malos" o socialmente dañinos deben estar representados en el mercado de las ideas" [43]. Lo anterior permite concluir que un fin esencial de la libertad de expresión consiste en proteger la expresión individual que la mayoría o cualquier otro sector social quisiera restringir.

Finalmente, debe considerarse la relación entre la libertad de expresión y el sistema jurídico. El derecho en occidente puede ser considerado como un sistema de pasos y procedimientos diseñado para encontrar soluciones a problemas complejos. Pero el derecho - en especial el constitucionalismo- también es una búsqueda para promover la equidad, exponer la corrupción, avanzar la justicia, preservar la libertad, controlar el poder y defender los derechos inalienables ${ }^{[44]}$.

En efecto, el sistema jurídico demanda que las personas argumenten e intercambien opiniones, después de todo, el proceso judicial no es nada diferente al conflicto entre dos visiones jurídicas. El derecho expresa su manifestación más viva, su calidad humana, en el intercambio de argumentos y opiniones, de ahí que el sistema jurídico regule y enseñe cómo discrepar ${ }^{[45]}$. Directa o indirectamente, todas las normas dependen de la voluntad de la democracia, y tal vez nunca hemos considerado el gran espacio jurídico que se abre a la transformación cuando la opinión de la población cambia por la expresión libre de un ciudadano ${ }^{[46]}$.

El fin del derecho - del constitucionalismo- en occidente es permitir que los hombres desarrollen sus facultades de manera libre y que en el gobierno prevalezca la deliberación sobre la imposición, la democracia sobre la tiranía. El derecho, como creación de la voluntad política democrática, tiene su origen en la expresión libre de los representantes electos, en la autonomía de las personas o en la manifestación de los servidores públicos, y en cualquiera de estas instancias la libertad de expresión es el cimiento a partir del cual se construye el edificio jurídico ${ }^{[47]}$.

No existe mayor peligro para el sistema jurídico de una democracia constitucional, que un pueblo inerte o un soberano indiferente. El orden que genera el derecho no se asegura únicamente con la represión del infractor. La mayor estabilidad para las normas es cuando estas incentivan el pensamiento, la esperanza y la imaginación libre; el miedo a las nuevas instituciones debe ser excluido del constitucionalismo, ningún gobierno democrático con vocación de permanencia se ha fundado en el miedo a la expresión libre de sus ciudadanos $^{[48]}$.

La historia del derecho en occidente ha sido el desplazamiento del error en las normas y en la jurisprudencia. En consecuencia, la libertad no debe ser temida por las normas, sino incentivada y protegida, así esta expresión sea una crítica a la visión jurídica actual. ${ }^{[49]}$

La herencia más preciada del derecho en occidente es la garantía constitucional de cada persona de expresar su opinión libremente. El control de la expresión es una marca del totalitarismo, sin que la democracia constitucional pueda reclamar alguna forma de censura. Las normas que garantizan la libertad de expresión no 
existen para evitar que los ciudadanos digan opiniones equivocadas, estas se establecen para que las personas puedan señalar libremente las posibles equivocaciones del Estado ${ }^{[50]}$.

\section{Los efectos prácticos de la libertad de expresión}

En esta parte se hará referencia a tres efectos prácticos de la libertad de expresión: (1) al uso de palabras ofensivas o fighting words, (2) la tensión entre el derecho a la honra y la libertad de expresión y (3) el discurso de odio o hate speech.

\section{El uso de palabras ofensivas o fighting words}

El 6 de abril de 1940, el testigo de Jehová Walter Chaplinsky pronunció un discurso donde se refería a las autoridades de la ciudad de New Hampshire, como "fascistas" y "estafadores malditos". El reverendo fue posteriormente arrestado y condenado por violar una norma estatal que prohibía el uso de palabras ofensivas en público. Su condena fue apelada, y el caso fue finalmente decidido en 1942 por la Corte Suprema de los Estado Unidos, ratificando la condena de Chaplinsky.

La Corte concluye que existe una categoría particular de discurso que puede ser válidamente limitado, la cual definió como fighting words o palabras ofensivas. Para la instancia de cierre, las palabras ofensivas

"tienen un valor social bajo y un direccionamiento leve hacia la verdad que cualquier beneficio que pueda derivarse de ellas, es claramente superado por el interés social de mantener el orden y la moralidad". ${ }^{[51]}$

En 1949, la misma Corte Suprema restringiría la teoría de las palabras ofensivas con la Sentencia de Terminiello vs. Chicago. En esta decisión, se revocó la condena del Padre Arthur Terminiello, quien fue arrestado y condenado por "vulnerar la paz" en la ciudad de Chicago al haber pronunciado un discurso ante una audiencia de 800 personas, en el cual aseguró que varios grupos raciales y políticos eran contrarios al bienestar del país.

En su argumento, la Corte considera que la libertad de expresión

“puede servir mejor su propósito, cuando se induce a una condición de inquietud, de insatisfacción en las condiciones de la sociedad o incluso cuando se incita a las personas a enojarse. El discurso suele ser provocativo y desafiante. Puede golpear prejuicios y preconceptos y tener efectos perturbadores profundos cuando presiona para la aceptación de una idea". ${ }^{[52]}$

La Corte limitó nuevamente la teoría de las palabras ofensivas en la decisión de Cohen vs. California de 1971. Este caso surge cuando Paul Cohen, un joven de 19 años, decidió vestirse con una chaqueta que tenía estampada la frase "a la mierda la conscripción", y al tratar de ingresar al palacio de justicia de San Francisco, los funcionarios públicos le impidieron el acceso bajo el argumento que las palabras en su chaqueta eran ofensivas.

Lo primero que hace la sentencia es limitar la teoría de fighting words a palabras que involucren un insulto personal y directo. Para la Corte, no se puede aceptar la sencilla suposición que se pueden prohibir palabras sin correr también el riesgo de suprimir ideas para concluir que una "verdad usual es que la vulgaridad de unas personas, es la lírica de otro" ${ }^{[53]}$.

Finalmente, en la Sentencia de R.A.V Petitioner vs. City of St. Paul Minnesota, la Corte estudió el caso de unos adolescentes que hicieron una cruz de manera rudimentaria para ser instalada e incendiada frente al patio de una familia afroestadounidense, en otras palabras, los adolescentes hicieron un símbolo de odio relacionado con Ku Klux Klan.

Las autoridades de Minnesota judicializaron a los adolescentes, al considerar que se trataba del despliegue de un símbolo que se sabía produciría rabia, alarma o resentimiento en razón a la raza de las personas. Luego la Corte Suprema revocó la condena bajo el argumento de que la libertad de expresión no les permitía a 
las autoridades estatales imponer prohibiciones especiales a las personas que expresaban sus opiniones sobre temas polémicos. Según la Corte, no es posible que, en una democracia constitucional, las normas autoricen un estilo libre y no regulado para un lado del debate, mientras que al otro se le exige seguir de la manera más estricta las reglas de decoro y urbanidad.

A una conclusión similar llegó la Corte Constitucional Colombiana, al determinar que la libertad de expresión

"incluye un aspecto negativo y uno positivo. El primero, comprende la facultad de expresar opiniones e ideas; el segundo protege la libertad de circular y recibir información y, como se indicó, tales dimensiones salvaguardan 'las expresiones ofensivas, chocantes, impactantes, indecentes, escandalosas, excéntricas o simplemente contrarias a las creencias y posturas mayoritarias, ya que la libertad constitucional protege tanto el contenido de la expresión como su tono". [54]

\section{La tensión entre el derecho a la honra y la libertad de expresión}

Las sentencias de la Corte Interamericana de Derechos Humanos (CtIDH) han reiterado la existencia de una dimensión individual y una social en la libertad de expresión. La primera hace referencia a la prohibición de impedir arbitrariamente la opinión de cualquier persona, así como la posibilidad de utilizar cualquier medio para difundirla. Por otro lado, la dimensión social de la libertad de expresión implica un derecho colectivo a recibir toda clase de información o expresión de pensamiento ${ }^{[55]}$.

La misma jurisprudencia reconoce que la libertad de expresión no es un derecho absoluto, esta garantía tiene y puede ser limitada, de ahí que el artículo 13.2 de la Convención Americana de Derecho Humanos prohíba la censura previa, pero también permita exigir responsabilidad frente al abuso del derecho a la libertad expresión. De particular interacción con la libertad de expresión es el derecho a la honra, reconocido en el artículo 11 de la Convención.

En efecto, el artículo 11 de la Convención prohíbe la injerencia arbitraria o abusiva en la vida privada, familiar y correspondencia de las personas, así como los ataques ilegales contra su honra o reputación. Lo anterior implica la existencia de un ámbito exento o inmune a la intervención u opinión de terceros —incluido el Estado- lo cual autoriza al sistema jurídico a adoptar medida para salvaguardar el derecho a la honra y a la privacidad ${ }^{[56]}$.

El anterior estándar de protección no es exclusivo de las Américas. El artículo 19(3) del Pacto Internacional de Derechos Civiles y Políticos (ICCPR) ${ }^{[57]}$ establece que el ejercicio del derecho a la libertad de expresión lleva consigo deberes y responsabilidades.

Ahora, las restricciones a la libertad de expresión tienen un carácter excepcional para la CtIDH, sin que puedan limitar el pleno ejercicio del derecho o convertirse en un mecanismo de censura previa ${ }^{[58]}$. Para el tribunal internacional, solo es posible limitar el derecho a la libertad de expresión a través de una ley tanto en sentido formal como material ${ }^{[59]}$.

Frente a la limitación de la libertad de expresión a través de un tipo penal —injuria o calumnia — la Corte considera que la norma punitiva debe satisfacer el principio de legalidad, es decir, formularse de manera expresa, precisa, taxativa y previa, con lo cual se garantice seguridad jurídica a los ciudadanos. ${ }^{[60]}$

Estas restricciones deben ser proporcionales, es decir, se requiere el análisis de:

“i) el grado de afectación de uno de los bienes en juego, determinando si la intensidad de dicha afectación fue grave, intermedia o moderada; ii) la importancia de la satisfacción del bien contrario, y iii) si la satisfacción de éste justifica la restricción del otro. En algunos casos la balanza se inclinará hacia la libertad de expresión y en otros a la salvaguarda del derecho a la honra”. ${ }^{[61]}$

En lo referente a las expresiones que critican o cuestionan la idoneidad de un funcionario público, sus decisiones o actos, la CIDH ha reconocido que estas tienen una mayor protección toda vez que incentivan y generan debate en la democracia. Este nivel de exposición — por demás voluntario— del servidor estatal 
implica un mayor grado de escrutinio, diferente al que se encuentra sometido un ciudadano privado, lo cual se justifica por el interés público que despierta la actividad del servidor ${ }^{[62]}$.

El escrutinio y evaluación de la labor de los funcionarios públicos fomenta la transparencia y promueve una gestión responsable en la administración pública, lo cual obliga a una mayor tolerancia frente a las opiniones hechas por los ciudadanos sobre al funcionario y a su labor ${ }^{[63]}$.

La crítica que debe ser tolerada por los funcionarios estatales es una demanda del pluralismo inherente a la democracia constitucional, la cual necesita de la libre circulación de "informes y opiniones sobre asuntos de interés público" ${ }^{[64]}$. Estas expresiones sobre asuntos de interés público, no solo son protegidas frente a la emisión de aquellas consideradas

"inofensivas o bien recibidas por la opinión pública, sino también la de aquellas que chocan, irritan o inquietan a los funcionarios públicos o a un sector cualquiera de la población”. [65]

En resumen, para el sistema interamericano las opiniones subjetivas sobre un servidor público, el agrado o desagrado de su gestión, su idoneidad o desempeño, no son objeto de juicios de veracidad o falsedad, toda vez que no son hechos, sino opiniones personales ${ }^{[66]}$.

El anterior estándar de protección es compartido por el sistema europeo de derechos humanos. En el caso Lingens vs. Austria, se decidió la responsabilidad penal de un periodista que había sido condenado por haber acusado a un ex primer ministro de oportunismo político, y de usar sus conexiones para evitar la investigación de los nexos de un aliado político con crímenes nazis.

La Corte Europea de Derechos Humanos concluyó que las normas austriacas que requerían la prueba de la veracidad de las afirmaciones de Lingens, operaban como una interferencia excesiva en su libertad de expresión $^{[67]}$. En otras palabras, para ambos sistemas regionales nadie puede ser objeto de responsabilidad por una simple opinión.

\section{El discurso de odio o hate speech}

Tal vez una de las expresiones más complejas en el pluralismo de la democracia moderna, es el denominado discurso de odio o hate speech. En él se expresa una opinión que difunde, incita, promueve o justifica el odio, la violencia o la discriminación, en contra de "una persona o grupo de personas por distintas razones" ${ }^{[68]}$.

Sin importar el emisor o destinatario, los discursos de odio

"no han tenido límites temporales o espaciales, fueron utilizados por los oficiales nazis en Alemania y por el Ku Klux Klan en Estado Unidos, así como por una amplia gama de actores en Bosnia durante los años noventa y en el genocidio en Ruanda en $1994 "[69]$.

Tanto el artículo 20 del ICCPR, y el artículo 4 del Convención Internacional sobre la Eliminación de todas las Formas de Discriminación Racial, obligan a los estados parte a criminalizar las expresiones que constituyan propaganda a la guerra o aboguen por el odio racial. Lo anterior, debe ser armonizado con el artículo 19(3) del ICCPR, donde se ordena que la restricción a la libertad de expresión debe ser lo menos invasiva posible para alcanzar el fin deseado. El uso de la libertad de expresión para incitar a la violencia es una ofensa criminal en casi todos los países, pero lograr el balance entre lo considerado como libertad de opinión y lo prohibido, es en la práctica algo difícil ${ }^{[70]}$.

Desde el punto de vista teórico, la posición liberal clásica sostiene que la censura causa más daño que beneficio cuando esta conlleva a la supresión de expresiones impopulares, pero legítimas, incluso a las críticas al establecimiento público. En palabras del filósofo John Rawls; "suprimir la libertad de expresión, incluida la expresión subversiva, implica siempre una supresión parcial de la democracia" ${ }^{[71]}$. En consecuencia, para 
el liberalismo clásico, la forma de combatir y demostrar la falsedad del discurso de odio es verificándolo con la realidad ${ }^{[72]}$.

Jeremy Waldron ha sugerido que el daño generado por el discurso de odio consiste en una contaminación moral que socava el bienestar público, la tolerancia y la inclusión, con lo cual se elimina la dignidad de la minoría atacada ${ }^{[73]}$. Esta situación amerita la censura del discurso de odio, después de todo, para Waldron

"las sociedades no se ordenan de manera adecuada por arte de magia. La funciona expresiva y disciplinaria de la ley, es necesaria como un ingrediente para hacer cambiar de opinión a ciudadanos racistas". ${ }^{[74]}$

Desde el punto de vista del derecho comparado, la jurisprudencia de los Estados Unidos ha generado un test para comprobar si el hate speech debe ser castigado o no. Esta medida fue adoptada con la sentencia de Brandenburg vs. Ohio de 1969.

La sentencia resolvió la responsabilidad de Clarence Brandenburg, un miembro del Ku Klux Klan, quien contactó a un medio de comunicación para que cubriera una reunión del Klan en la cual pronunció un discurso donde, después de enumerar una serie de insultos raciales despectivos, aseguro que "es posible que deba tomarse alguna venganza" ${ }^{[75]}$.

Clarence fue condenado bajo la teoría del "peligro claro y presente", la cual fue establecida en la sentencia Whitney vs. California de 1927, según la cual el Estado tiene la potestad de castigar a quienes abusan de su derecho a la libertad de expresión, por declaraciones contrarias al bienestar general que "tienden a incitar al crimen, perturbar la paz pública o poner en peligro el funcionamiento del gobierno" ${ }^{[76]}$ o incluso que amenacen su derrocamiento.

La Corte Suprema varía su jurisprudencia y concluye que la teoría del "peligro claro y presente" debe ser reemplazada por un test, según el cual el Estado puede prohibir ciertos discursos, usar la fuerza y castigar penalmente al emisor, si se satisfacen dos elementos: (1) el discurso debe estar "dirigido a incitar o producir una acción ilegal inminente" ${ }^{[77]}$, y (2) que sea probable que el discurso incite o produzca la acción ilegal.

Bajo el "Brandenburg test", las expresiones de odio que no cumplan con las dos condiciones son consideradas parte de la libertad de expresión y no pueden ser castigadas.

Después de la aplicación del referido test en la sentencia de Hess vs. Indiana de 1973, se absolvió a un manifestante de la Universidad de Indiana que dijo: "nos tomaremos la jodida calle de nuevo ahora o más tarde". Para la Corte la expresión del universitario estaba protegida bajo el test de Brandenburg, ya que su discurso "no equivalía a nada más que la defensa de acciones ilegales en algún momento indefinido en el futuro" $"$ [78].

El Tribunal concluyó que al no haber evidencia o inferencia racional entre el actuar y sus palabras, estas no tenían la intención de producir una acción ilegal inminente, por lo cual no podía castigarse la expresión de Hess.

Finalmente, en la Sentencia de NAACP vs. Claiborne Hardware Co. de 1982, la Corte revisó la conducta de Charles Evers, quien amenazó con recurrir a la violencia contra aquellos que se negaron a boicotear los negocios de propiedad de miembros de la raza blanca en Mississippi. La Corte Suprema aplicó el test de Brandenburg, y encontró que el discurso estaba protegido puesto que la retórica de Evers fue improvisada, y si bien esta era fuerte y directa, el Estado no puede entrometerse en la forma como un expositor estimula a su audiencia, siempre y cuando esta no incite a una acción ilegal inminente.

En resumen, puede adoptarse la conclusión hecha la Corte Suprema del Canadá, en la cual se determinó que el propósito de la libertad de expresión "es permitir la libre expresión hasta el fin de promover la verdad, la participación política o social y la realización personal. Ese propósito se extiende a la protección de las creencias de las minorías que la mayoría considera erróneas o falsas" ${ }^{\text {"[79] }}$. 


\section{Conclusión}

La libertad de expresión se ha formulado de una manera general, tanto en la Constitución Política de 1991, como en los múltiples tratados y convenios internacionales que protegen ese derecho en el plano global y regional. Esta formulación implica una indeterminación ya que no existe un punto fijo de realización del derecho, sólo un requerimiento que exige su satisfacción en el máximo grado posible, que le dé a la norma positiva aplicada la mejor luz moral posible ${ }^{[80]}$.

Desde un sentido más práctico, principios como la libertad de expresión son elementos del derecho que inclinan la decisión en un sentido u otro, pero la persuasión de los principios no es concluyente, y estos no dejan de existir por no ser aplicados en una decisión o cuando se reconoce que su valor no es absoluto. ${ }^{[81]}$

Como derecho humano, la libertad de expresión es una norma abierta a la interpretación, lo cual deja a cada Estado un amplio margen en su aplicación; después de todo, los derechos humanos implementan un lenguaje cosmopolita que permite el multiculturalismo ${ }^{[82]}$. En consecuencia, la interpretación que se da a los derechos, determina el campo de protección reconocido en cada país ${ }^{[83]}$, aun para una garantía universal como lo es la libertad de expresión ${ }^{[84]}$.

Ahora, en tratándose de la interpretación de un derecho, es imposible crear una métrica o fórmula matemática que asegure su correcta interpretación ${ }^{[85]}$. No obstante a lo anterior, la amplitud interpretativa no significa que cualquier entendimiento puede atribuirse al derecho o principio que se interpreta. Sin duda, existen razones objetivas que apoyan y generan una convergencia sobre la manera adecuada en que se deben aplicar los derechos ${ }^{[86]}$.

En términos simples, que los derechos humanos requieran de interpretación no puede ser un argumento para el relativismo o una patente de corso para que a ellos les sea atribuido cualquier entendimiento. Un dictador que asesina y encarcela a las personas que le incomodan merece el repudio universal ${ }^{[87]}$.

Así las cosas, la interpretación que se propone para la libertad de expresión como para cualquier otro derecho humano, es que esta sea una lectura filosófica o moral ${ }^{[88]}$.

Para apoyar esta forma de interpretación, se propone que, al ser la libertad de expresión un derecho humano, esta garantía hace parte de un grupo de principios morales internacionales que sirven - de manera primaria - para juzgar la conducta del Estado, y, en segundo lugar, se mostrará como la interpretación es una empresa jurídica que debe realizarse en términos de filosofía política o moralidad jurídica.

La primera cualidad de todo derecho humano es que estos son principios internacionales que se adoptan a un nivel nacional, que se usan para evaluar a un Estado y a la sociedad en general sobre el nivel de protección que se le reconoce a las personas en un momento en particular, con lo cual se generan expectativas legítimas sobre cómo se comportan los agentes del Estados, en especial quienes administran justicia ${ }^{[89]}$.

La existencia de un derecho humano significa que el Estado o cualquier otro agente, tiene la obligación de abstenerse de interferir en el espacio protegido por la norma internacional ${ }^{[90]}$. Por otro lado, cuando existe una interferencia, se deben proporcionar las razones que justifican el actuar, de tal manera que el agente que interfiera presente una posición jurídica lo suficientemente válida a la luz del orden constitucional y legal. ${ }^{\text {[91] }}$

La interpretación de un derecho humano tiene su punto de partida en el reconocimiento de que se trata de derechos que tienen sus raíces en una moralidad interpersonal ${ }^{[92]}$. Lo cual declara que la lectura de un derecho humano, para su aplicación en un caso, es una aceptación de una moralidad internacional que se ha establecido en el tratado que consagra el derecho. Sin duda, esto no pretende negar las profundas diferencias que existen entre las personas y sus visiones jurídicas, pero sí tiene como finalidad reconocer a todas las personas con los mismos derechos y la esperanza de reducir el desacuerdo frente a la consideración de las personas como agentes morales $^{[93]}$. 
Si los derechos humanos se fundamentan en la consideración de las personas como agentes morales, lo cual limita o constriñe el actuar del Estado o de las personas de cierta manera, la interpretación de los derechos humanos debe ser una interpretación moral, después de todo, cuando se apela a derechos como la libertad de expresión, la vida, el debido proceso o la libertad religiosa, se utilizan conceptos y no concepciones ${ }^{[94]}$.

Lo anterior no pretende asegurar que existe una sola teoría interpretativa de los derechos. Sí existe un asunto con pluralidad de doctrinas es el campo de la interpretación ${ }^{[95]}$, pero se plantea que ante múltiples alternativas se debe escoger aquella que sea más favorable para la protección del derecho, esto en virtud del principio de escoger la interpretación más favorable para el ser humano. ${ }^{[96]}$

Por ser los derechos humanos un reclamo universal para la protección del individuo ${ }^{[97]}$, su interpretación, demanda del operador jurídico las razones que han llevado a la conclusión. Esto es lo que se denomina interpretación moral, una búsqueda crítica del mejor significado posible, de tal forma que la decisión que determina el entendimiento del derecho, de a la norma positiva la mejor luz moral posible ${ }^{[98]}$.

Esta forma de interpretar demanda del operado jurídico — en especial de los jueces - la posibilidad de poder decidir o argumentar de manera libre e independiente y de valorar las condiciones del caso, sin miedo a la censura o a la persecución. Después de todo, el significado de un derecho humano para un caso en concreto rara vez es simple, pero reiteradamente resulta controversial ${ }^{[99]}$.

Lo anterior demanda del sistema constitucional y legal dos condiciones. En primer lugar - y sin importar la tradición jurídica - el sistema debe reconocer a los derechos humanos como parte de él, como derecho coercible si se quiere, y, en segundo lugar, el sistema debe proveer un remedio o acción, en caso de vulneración de los derechos ${ }^{[100]}$.

La interpretación moral acepta que los derechos humanos pueden ser interpretados de manera diferente en cada contexto local. ${ }^{[101]}$ Lo que requiere esta visión, es que cada vez que un derecho humano es aplicado, el intérprete debe dar las razones por las cuales atribuye una concepción en particular, al concepto universal que es el derecho humano. El dar razones objetivas sobre la posición adoptada es el primer paso para combatir el extremismo $^{[102]}$. En consecuencia, se puede concluir que los derechos humanos tienen sustento en "buenos argumentos morales que pueden ser apoyados por varias religiones y filosofías del mundo" ${ }^{[103]}$.

En resumen, cuando se ha llegado a una visión sobre un derecho, esta interpretación genera un debate que se extenderá más allá de los salones de clase, llegará a los medios de comunicación, y generará actitudes judiciales y políticas en la población, así como en los encargados de reafirmar o modificar la decisión, e invitará al apoyo y a la contradicción de la interpretación ${ }^{[104]}$.

Por ser los derechos humanos - como lo es la libertad de expresión — instrumentos universales de igualdad, estos sirven como crítica a la tiranía jurídica o política ${ }^{[105]}$. En consecuencia, cuando una interpretación inadecuada de un derecho se apropia del concepto, evitando que se extienda al máximo posible su ámbito de protección, es igual a decir que existe una interpretación que falla en dar las razones morales adecuada para sustentar la determinación ${ }^{[106]}$. De esta forma se genera una objeción moral a la interpretación de un derecho que permite a la injusticia permanecer en el sistema jurídico o político ${ }^{[107]}$.

Lo que al final se argumenta es que el derecho a la libertad de expresión, como cualquier otro derecho humano, tiene la capacidad de facilitar el cambio en los contextos donde se necesita con mayor urgencia ${ }^{[108]}$. Capacidad que disminuye si la interpretación que se atribuye se limita a una tradición política o jurídica, que no permite la expansión de la esfera de protección de los derechos. ${ }^{[109]}$

La interpretación moral de la libertad de expresión es una invitación para mantener vigente un derecho humano frente a las cambiantes realidades de la sociedad. En esta garantía se mantiene la eterna perspectiva del pluralismo de la democracia, un santuario silencioso en el que podemos encontrar un espacio para elevarnos por encima de nuestras mentes acosadas y perplejas, y ver un valor estable que ninguna preocupación egoísta y tímida puede hacer tambalear, porque es la posesión permanente y duramente ganada de la humanidad. 


\section{Agradecimiento}

Agradezco a JDL la inspiración para este artículo, frente a sus comentarios mi respuesta son estas palabras; donde reafirmó que no creo en lo que dice, pero defenderé su derecho a decirlo.

\section{Bibliografía}

"La Última Tentación de Cristo" (Olmedo Bustos y otros) vs. Chile, Sentencia de 5 de febrero de 2001 (Fondo, Reparaciones y Costas). Comisión I.D.H., Serie C n. ${ }^{\circ} 73$, OEA párr. 64.

"Masacre de Mapiripán" vs. Colombia, Sentencia de 15 septiembre de 2005, Comisión I.D.H., OEA párr. 106 (2005). Abraham Lincoln, Discurso de Gettysburg, 19 de noviembre de 1863.

Alexander M. Bickel, The morality of consent, Yale University Press, 6-8 (1976).

Alexander Meiklejohn, Political freedom, Harper (1960).

Andrei Dmitrievich Sakharov, Reflections on Progress, Peaceful Coexistence, and Intellectual Freedom, 22 de Julio de 1968.

Anne Weber, Manual on hate speech, Council of Europe Publishing, 28-63 (2009). http://icm.sk/subory/Manual_ on_hate_speech.pdf

Antonio Cassese, Human Rights in a Changing World, Temple University Press, 50 (1990).

ARTICLE 19, Los Principios de Camden sobre la libertad de expresión y la igualdad, Global Campaign for free expression (2009).

Brandenburg vs. Ohio, 395 U.S. 444 (more) 89 S. Ct. 1827; 23 L. Ed. 2d 430; 1969 U.S. LEXIS 1367; 48 Ohio Op. 2 d 320 (1969).

Beth A. Simmons, Mobilizing for Human Rights: International Law in Domestic Politics, Cambridge University Press, 369-371 (2009). https://doi.org/10.1017/CBO9780511811340

Claude Reyes y otros vs. Chile, Sentencia de 19 de septiembre de 2006 (Fondo, Reparaciones y costas), Corte I.D.H., Serie C n. ${ }^{\circ}$ 151, OEA párr. 87 (2006).

Comisión I.D.H., Relatoría Especial para la Libertad de Expresión. Marco jurídico interamericano sobre el derecho a la libertad de expresión. OEA/Ser.L/V/II CIDH/RELE/INF. 2/09 (2009).

Consejo de Europa, Convenio Europeo de Derechos Humanos, art. 10, 1950. https://www.echr.coe.int/Document s/Convention_SPA.pdf

Consejo de la Liga de los Estados Árabes, Carta árabe de derechos humanos, art. 27, 15 de marzo de 2008.

Constitución Política de Colombia [Const.]. 7 de julio de 1991 (Colombia).

Corte Constitucional de Colombia. Sala novena de revisión. Sentencia T-089 de 2019. Expediente No. T- 6.787.741, Acción de tutela formulada por Hernán Darío Ospina Reyes contra la Universidad Santiago de Cali. (M. P. Alberto Rojas Ríos, 1 marzo de 2019). http://www.corteconstitucional.gov.co/relatoria/2019/t-089-19.htm

Corte Constitucional de Colombia. Sala segunda de revisión. Sala de lo Contencioso Administrativo. Sección Tercera. Sentencia T-391 de 2007. Acción de tutela instaurada por Radio Cadena Nacional S.A. - RCN en contra del Consejo de Estado (M. P. Dr. Manuel José Cepeda Espinosa; 22 de mayo de 2007).

Corte Constitucional de Colombia. Sala segunda de revisión. Sentencia T-155 de 2019. Expediente No. T-6856856, Acción de tutela instaurada por Sigifredo Fonseca González contra Jael Johana Castro León (M. P. Diana Fajardo Rivera, 4 de abril de 2019). http://www.corteconstitucional.gov.co/relatoria/2019/T-155-19.htm

Corte Suprema de Canadá, R. vs. Zundel, 2 S.C.R 21811 (1992).

Corte Suprema de Canadá. Committee for the Commonwealth of Canadá v. Canadá, Sentencia 20334, 1 SCR 139, 25 de enero de 1991.

Corte Suprema de Canadá. Zundel v. Canada, Comm. HRC 1341/2005, U.N. Doc. A/62/40, Vol. II, at 511 (2007). 
David S. Bogen, The origins of freedom of speech and press, 42 Maryland Law Review, n. ${ }^{\circ}$ 3, 429 (1983). https://digita lcommons.law.umaryland.edu/mlr/vol42/iss3/3/

Declaración y Programa de Acción de Viena, Res, A. G. 48/121, Conferencia Mundial de Derechos Humanos (1993).

Denis Galligan \& Deborah Sander, Implementing Human Rights, en Human Rights Brought Home: Socio-Legal Perspectives of Human Rights in the National Context 23-56 (Simon Halliday \& Patrick Schmidt eds., 2004).

Dominic McGoldrick. Though, Expression, Association, and Assembly, en International Human Rights Law 230 (Daniel Moeckli, Sangeeta Shah \& Sandesh Sivakumaran eds., 2014).

Drew Gilpin Faust. “Getting Closer": Remarks for the Bicentennial of Harvard Law School. Drew gilpin faust, Sanders theatre, Cambridge, Mass. https://www.harvard.edu/president/speech/2017/getting-closer-remarks-for-bicent ennial-harvard-law-school

Edith Hamilton, The Greek way, Turner, Fondo de Cultura Económica (1a. ed., 1930).

Edmund Randolph, Essay on the revolutionary history of Virginia, 44 Virginia Magazine of History and Biography, $\mathrm{n}$. ○ 1, 294-315 (1936).

Eduardo Andrés Bertoni, Libertad de expresión en el Estado de derecho. Doctrina y jurisprudencia nacional, extranjera e internacional, Editores del Puerto, 179 (2007).

Fontevecchia y D'Amico vs. Argentina, Sentencia de 29 de noviembre de 2011, Comisión I.D.H., Series C n. ${ }^{\circ} 238$, OEA párr. 48 y 49 (2011).

Frédéric Mégret, Nature of Obligations, en International Human Rights Law 99-112 (Daniel Moeckli, Sangeeta Shah \& Sandesh Sivakumaran eds., 2014).

George Ulrich, Epilogue: widening the perspective on the local relevance of human rights, En The Local Relevance of Human Rights 337-360 (Koen De Feyter, Stephan Parmentier, Christiane Timmerman \& George Ulrich eds., 2011). https://doi.org/10.1017/CBO9780511841842.015

Herrera Ulloa vs. Costa Rica, Sentencia de 2 de julio de 2004 (Excepciones Preliminares, Fondo, Reparaciones y Costas), Comisión I.D.H., Serie C n. ${ }^{\circ} 107$, OEA párr. 120 (2004).

Hess Vs. Indiana. 414 U.S. 105 (more) 94 S. Ct. 326; 38 L. Ed. 2d 303; 1973 U.S. LEXIS 177 (1973)

Hugo Bustíos Saavedra vs. Perú, Caso 10.548, Comisión I.D.H., Informe n. ${ }^{\circ}$ 38/97, OEA párr. 72 (1997). https://w ww.cidh.oas.org/annualrep/97span/Peru10.548.htm

Ivcher Bronstein vs. Perú, Sentencia de 6 de febrero de 2001 (Reparaciones y Costas), Comisión I.D.H., Serie C n. ${ }^{\circ}$ 74, párr. 146.

James W. Nickel, Making sense of human rights, Ed. Wiley Blackwell, 172 (2007).

Jeremy Waldron, 2009 Oliver Wendell Holmes Lectures Dignity and Defamation: The Visibility of Hate, Harvard Law School (2009). https://harvardlawreview.org/wp-content/uploads/pdfs/vol123_waldron.pdf

Jeremy Waldron, Cap. XI, la participación: el derecho de los derechos, en Derechos y desacuerdos 277-304 (Ed. Marcial Pons, 2005).

Jeremy Waldron, The harm in hate speech, Harvard University Press, 4, 5, 81, 94-95 (2012). https://doi.org/10.415 9/harvard.9780674065086

John Rawls, A theory of justice, Harvard University Press (1971).

John Stuart Mill, On Liberty (1 ${ }^{\text {a }}$. ed., Ed. John W. Parker and Son, 1859).

John Tilley, Cultural Relativism 22 Human Rights Quarterly, n. ${ }^{\circ}$ 2, 501-547 (2000). https://doi.org/10.1002/9781 405165518.wbeosc176.pub2

Jonathan I. Charney, Universal International Law, 87 The American Journal of International Law, n. ${ }^{\circ}$ 4, 529-551 (1993). https://doi.org/10.2307/2203615

Juan I de Inglaterra \& Stephen Langton, arzobispo de Canterbury, Magna Carta Libertatum, 15 de junio de 1215.

Jürgen Habermas y William Rehg, Constitutional democracy: A paradoxical union of contradictory principles? 29 Political Theory, n. ${ }^{\circ}$ 6, 766-781 (2001). https://doi.org/10.1177/0090591701029006002

Jürgen Habermas, Time of transitions, Polity, 114 (2006). 
Kimel vs. Argentina, Sentencia 2 de mayo de 2008 (Fondo, reparaciones y costas), Comisión I.D.H., Serie C n. ${ }^{\circ}$ 177, OEA párr. 51, 52, 84, 87 y 93 (2008).

La Colegiación Obligatoria de Periodistas (Arts. 13 y 29 Convención Americana sobre Derechos Humanos), Opinión Consultiva OC-5/85, Corte I.D.H. Serie A No. 5, párr. 30 (13 de noviembre de 1985).

La expresión "leyes" en el artículo 30 de la Convención Americana sobre Derechos Humanos (Art. 30 n. 22 Corte Interamericana de Derechos Humanos), Opinión Consultiva OC-6/86, Corte I.D.H. (9 de mayo de 1986).

Lillian R. BeVier, The First Amendment and Political Speech: An Inquiry into the Substance and Limits of Principle, 30 Stanford Law Review, n. ${ }^{\circ}$ 2, 299 (1978). https://doi.org/10.2307/1228035

Louis Henkin, The Universality of the Concept of Human Rights, 506 The ANNALS of the American Academy of Political and Social Science, n. ${ }^{\circ} 1,10-16$ (1989). https://doi.org/10.1177/0002716289506001002

Martin Loughlin, Foundations of public law, Oxford University Press, 353-373 (2010). https://doi.org/10.1093/acp rof:oso/9780199256853.001.0001

Martin Loughlin, The idea of public law, Oxford University Press, 153-163 (2004). https://doi.org/10.1093/acprof: oso/9780199274727.003.0009

Michael Freeman, Universalism of human rights and cultural relativism, en Routledge Handbook of International Human Rights Law (Scott Sheeran \& Sir Nigel Rodley eds., 2013).

Michael J. Perry, Noninterpretive review in human rights cases: A functional justification, 56 New York University Law Review, n. ${ }^{\circ}$ 2, 278-312 (1981).

Norberto Bobbio, The age of rights, 9-14 (Allan Cameron trans., 1996).

Oliver Wendell Holmes Jr., The path of the law, 10 Harvard Law Review, n. ${ }^{\circ}$ 8, 457 (1897). https://doi.org/10.2307 $/ 1322028$

Organización de Estados Americanos, Convención Americana sobre Derechos Humanos (Pacto de San José), art. 13, 18 de julio de 1978.

Organización de las Naciones Unidas, Convención para la Prevención y la Sanción del delito de genocidio, 9 de diciembre de 1948. https://www.icrc.org/es/doc/resources/documents/misc/treaty-1948-conv-genocide-5td m6h.htm

Organización para la Unidad África, Carta africada de derechos humanos y de los pueblos, art. 9, 21 de octubre de 1986. http://www.derechoshumanos.net/normativa/normas/africa/CAFDH/1981-CAFDH.htm

Pacto Internacional de Derechos Civiles y Políticos, Res. A. G. 2200 A (XXI), O. N. U. Doc. A/RES/2200A(XXI) (1966).

Palamara Iribarne vs. Chile, Sentencia de 22 de noviembre de 2005 (Fondo, Reparaciones y Costas), Comisión I.D.H., Serie C n. ${ }^{\circ}$ 135. párr. 79 (2004).

Paul Schiff Berman, A Pluralist Approach to International Law, 32 Yale Journal of International Law, n. ${ }^{\circ}$, 301-311 (2007). https://digitalcommons.law.yale.edu/yjil/vol32/iss2/3

Ricardo Canese vs. Paraguay, Sentencia de 31 de agosto de 2004 (Fondo, Reparaciones y Costas) Comisión I.D.H., Serie C n. ${ }^{\circ} 111$, OEA párr. 95 (2004).

Richard Lappin, Would External Intervention by Military Force to Protect Civilians in Syria be Legally Justified? 8 Central European Journal of International and Security Studies, n. 4 , 137-151 (2014). http://www.cejiss.org/s tatic/data/uploaded/1425903401160568/Article\%2007.pdf

Robert C. Post, A progressive perspective on freedom of speech, en The Constitution in 2020, 179-186 (Jack M. Balkin and Reve B. Siegel eds., 2009).

Robert H. Bork, Neutral principles and some first amendment problems, 47 Indiana Law Journal, n. 1 (1971).

Robert Skipper, Mill and Pornography, 103 Ethics, n. 4 4, 726-730 (1993). https://doi.org/10.1086/293550

Ronald Dworkin, A Matter of Principle, Harvard University Press, 143-145, 165 (1985).

Ronald Dworkin, Freedom's law: The moral reading of the American Constitution, Harvard University Press, 345 (1996). 
Ronald Dworkin, Taking rights seriously, Harvard University Press, 21-22 (1977).

Rory O'connell, Let's Talk: Dealing with Difference in Human Rights Law, en The Tension Between Group Rights and Human Rights: A Multidisciplinary Approach (Koen De Feyter \& George Pavlakos eds., 2008).

Sally Engle Merry, Transnational Human Rights, and Local Activism: Mapping the Middle, 108 American Anthropologist, n. ${ }^{\circ}$ 1, 38, 41 (2006). https://doi.org/10.1525/aa.2006.108.1.38

Sotirios A. Barber \& James E. Fleming, Constitutional interpretation: The basic questions, Oxford University Press, 26-29 (2007).

Stephen L. Newman, Finding the Harm in Hate Speech: An Argument against Censorship, 50 Canadian Journal of Political Science, n. ${ }^{\circ}$ 679-697 (2017). https://doi.org/10.1017/S0008423916001219

Suprema Corte de los Estados Unidos, American Communications Association vs. Douds, 339 U.S. 382, 442-43 (1950). 70 S. Ct. 674; 94 L. Ed. 925; U.S. LEXIS 2530; 18 Lab. Cas. (CCH) párr. 65, 760; 26 L.R.R.M. 2084 (1950). https://supreme.justia.com/cases/federal/us/339/382/

Suprema Corte de los Estados Unidos, Chaplinsky vs. New Hampshire, 315 U.S. 56862 S., Ct. 766; 86 L. Ed. 1031; U.S. LEXIS 851 (1942). https://www.courtlistener.com/opinion/103632/chaplinsky-v-new-hampshire/

Suprema Corte de los Estados Unidos, Cohen vs. California, 403 U.S. 15 (1971), 91 S. Ct. 1780; 29 L.2d 284; 1971 U.S. LEXIS 32. https://www.courtlistener.com/opinion/108360/cohen-v-california/

Suprema Corte de los Estados Unidos, FCC vs. Pacifica Foundation, 438 U.S. 7268 S. Ct. 3026; 57 L. Ed. 2d 1073; U.S. LEXIS 135; 43 Rad. Reg. 2d (P \& F) 493; 3 Media L. Rep. 2553 (1978).

Suprema Corte de los Estados Unidos, Harper \& Row, Publishers, Inc. vs. Nation Enterprises, 471 U. S. 539, 559 (1985). https://supreme.justia.com/cases/federal/us/471/539/

Suprema Corte de los Estados Unidos, Hustler Magazine and Larry C. Flynt, Petitioners vs. Jerry Falwell, 485 U.S. 46, 108 S. Ct. 876; 99 L. Ed. 2d 41; U.S. LEXIS 941; 56 U.S.L.W. 4180; 14 Media L. Rep. 2281 (1988).

Suprema Corte de los Estados Unidos, Janus vs. american federation of state, county, and municipal employees, council 31, et al. 2017. https://www.oyez.org/cases/2017/16-1466

Suprema Corte de los Estados Unidos, Miami Herald Publishing Co. vs. Tornillo, 418 U. S. 241, 256-257 (1974). ht tps://supreme.justia.com/cases/federal/us/418/241/

Suprema Corte de los Estados Unidos, Pacific Gas \& Electric Co. vs. Public Utilities Commission of California, 475 U. S. 1, 9 (1986). https://supreme.justia.com/cases/federal/us/475/1/

Suprema Corte de los Estados Unidos, Riley vs. National Federation of Blind of N. C., Inc., 487 U. S. 781, 796-797 (1988). https://supreme.justia.com/cases/federal/us/487/781/

Suprema Corte de los Estados Unidos, Terminiello vs. City of Chicago, 337 U.S. 1, 69 S. Ct. 894; 93 L. Ed. 1131; U.S. LEXIS 2400. (1949). https://www.courtlistener.com/opinion/104668/terminiello-v-chicago/

Suprema Corte de los Estados Unidos, West Virginia State Board of Education vs. Barnette, 319 U. S. 624, 642 (1943). https://supreme.justia.com/cases/federal/us/319/624/

Suprema Corte de los Estados Unidos, Whitney vs. California, 274 U.S. 357, 47 S. Ct. 641; 71 L. Ed. 1095, U.S. LEXIS 1011 (1927). https://www.courtlistener.com/opinion/101097/whitney-v-california/

Suprema Corte de los Estados Unidos, Wooley vs. Maynard, 430 U. S. 705, 714 (1977). https://supreme.justia.com/ cases/federal/us/430/705/

Tamara Relis, Human rights and southern realities, 33 Human Rights Quarterly, n. ${ }^{\circ}$ 2, $519-520$ (2011). https://doi.o $\mathrm{rg} / 10.1353 / \mathrm{hrq} .2011 .0016$

Terrance Sandalow, Constitutional interpretation, 79 Michigan Law Review, 1033-1072 (1981). https://doi.org/10.2 $307 / 1288056$

Theo Van Boven, Categories of Rights, en International Human Rights Law 150-152 (Daniel Moeckli, Sangeeta Shah \& Sandesh Sivakumaran eds., 2014).

Thomas Irwin Emerson, The system of freedom of expression, Random House, 6-7, 62-63 (1970).

Thomas Jefferson, A Bill for Establishing Religious Freedom, 545 (1779). https://founders.archives.gov/documents/ Jefferson/01-02-02-0132-0004-0082 
Tribunal del Distrito de los Estado Unidos para el Distrito Sur de Nueva York, Oliver Wendell Holmes Jr. Abrams vs. United States, 250 US 61640 S. Ct. 17; 63 L. Ed. 1173, US LEXIS 1784 (1919).

Tribunal Estatal de Hamburgo, Sentencia BVerfGE 7, 198 [Lüth]; 22 de noviembre de 1951.

Tribunal Europeo de Derechos Humanos [CEDH]. Lingens vs. Austria, fondo y reparación, aplicación n. ${ }^{\circ}$ 9815/82, asunto n. ${ }^{\circ}$ 12/1984/84/131, A / 103, IHRL 58 (CEDH 1986), [1986] CEDH 7, (1986) 8 EHRR 407, (1986) 8 EHRR 103, (1992) 88 ILR 513, 8 de julio de 1986.

Vito J. Titone, State constitutional interpretation: The search for an anchor in a rough sea, 61 St. John's Law Review, n. ${ }^{\circ}$ 3, 431-472 (1987). https://scholarship.law.stjohns.edu/lawreview/vol61/iss3/4

\section{Notas}

* Artículo de reflexión.

[1] Edith Hamilton, The Greek Way, Turner, Fondo de Cultura Económica (1a. ed., 1930).

[2] John Stuart Mill, On Liberty (1ª. ed., Ed. John W. Parker and Son, 1859).

[3] Tribunal del Distrito de los Estado Unidos para el Distrito Sur de Nueva York, Oliver Wendell Holmes Jr. Abrams v. United States, 250 US 61640 S. Ct. 17; 63 L. Ed. 1173, US LEXIS 1784 (1919).

[4] Constitución Política de Colombia [Const]. 7 de julio de 1991 (Colombia).

[5] Supra nota 3.

[6] Consejo de Europa, Convenio Europeo de Derechos Humanos, art. 10, 4 de septiembre de 1950; Organización para la Unidad África, Carta africada de derechos humanos y de los pueblos, art. 9, 21 de octubre de 1986; Consejo de la Liga de los Estados Árabes, Carta árabe de derechos humanos, art. 27, 15 de marzo de 2008.

[7] David S. Bogen, The Origins of Freedom of Speech and Press, 42 Maryland Law Review, n. ${ }^{\circ}$ 3, 429 (1983).

[8] Una de las primeras formas en que se protegió la libertad de expresión, correspondió al constitucionalismo consuetudinario inglés. Juan I de Inglaterra \& Stephen Langton, arzobispo de Canterbury, Magna Carta Libertatum, 15 de junio de 1215.

[9] Edmund Randolph, Essay on the revolutionary history of Virginia, 44 Virginia Magazine of History and Biography, n. ${ }^{\circ}$, 294-315 (1936).

[10] David S. Bogen, supra nota 7.

[11] Robert C. Post, A progressive perspective on freedom of speech, en The Constitution in 2020, 179-186 (Jack M. Balkin and Reve B. Siegel eds., 2009).

[12] Ronald Dworkin, Taking rights seriously, Harvard University Press, $21-22$ (1977).

[13] Michael J. Perry, Noninterpretive review in human rights cases: A functional justification, 56 New York University Law Review, n.o 2, 278-312 (1981).

[14] Terrance Sandalow, Constitutional interpretation, 79 Michigan Law Review, 1033-1072 (1981); Vito J. Titone, State constitutional interpretation: The search for an anchor in a rough sea, 61 St. John's Law Review, n. ${ }^{\circ} 3,431-472$ (1987). Sobre la adaptabilidad de los derechos humanos se puede consultar: Tamara Relis, Human Rights and Southern Realities, 33 Human Rights Quarterly, n. ${ }^{\circ}$, 519-520 (2011) y Denis Galligan \& Deborah Sander, Implementing Human Rights, En Human Rights Brought Home: Socio-Legal Perspectives of Human Rights in the National Context 23-56 (Simon Halliday \& Patrick Schmidt eds., 2004).

[15] Organización de Estados Americanos, Convención Americana sobre Derechos Humanos (Pacto de San José), art. 13, 18 de julio de 1978.

[16] Committee for the Commonwealth of Canadá v. Canadá, Sentencia 20334, 1 SCR 139, 25 de enero de 1991 
[17] Wooley vs. Maynard, 430 U. S. 705, 714 (1977); véase también Riley vs. National Federation of Blind of N. C., Inc., 487 U. S. 781, 796-797 (1988); Harper \& Row, Publishers, Inc. v. Nation Enterprises, 471 U. S. 539, 559 (1985); Miami Herald Publishing Co. vs. Tornillo, 418 U. S. 241, 256-257 (1974); Pacific Gas \& Electric Co. vs. Public Utilities Commission of California, 475 U. S. 1, 9 (1986) y Janus vs. American federation of state, county, and municipal employees, council 31, et al. 2017.

[18] Janus vs. American federation of state, op. cit.; Riley vs. National Federation of Blind of N. C., op. cit.

[19] Thomas Jefferson, A Bill for Establishing Religious Freedom, 545 (1779).

[20] Comisión I.D.H., Relatoría Especial para la Libertad de Expresión. Marco jurídico interamericano sobre el derecho a la libertad de expresión. OEA/Ser.L/V/II CIDH/RELE/INF. 2/09 párr. 69 (2009).

[21] Organización de las Naciones Unidas, Convención para la Prevención y la Sanción del delito de genocidio, 9 de diciembre de 1948; Corte Constitucional de Colombia. Sentencia T-089 de 2019, acción de tutela formulada por Hernán Darío Ospina Reyes contra la Universidad Santiago de Cali. (M. P. Alberto Rojas Ríos, 1 marzo de 2019); Corte Constitucional de Colombia. Sala segunda de revisión. Sentencia T-155 de 2019, acción de tutela instaurada por Sigifredo Fonseca González contra Jael Johana Castro León (M. P. Diana Fajardo Rivera, 4 de abril de 2019).

[22] Suprema Corte de los Estados Unidos, West Virginia State Board of Education v. Barnette, 319 U. S. 624,642 (1943).

[23] Theo Van Boven, Categories of Rights, en International Human Rights Law 150-152 (Daniel Moeckli, Sangeeta Shah \& Sandesh Sivakumaran eds., 2014).

[24] Tribunal Estatal de Hamburgo, Sentencia BVerfGE 7, 198 [Lüth]; 22 de noviembre de 1951.

[25] Theo Van Boven, supra nota 23, 150-152.

[26] Declaración y Programa de Acción de Viena, Res, A. G. 48/121, Conferencia Mundial de Derechos Humanos (1993).

[27] Jürgen Habermas, Time of transitions, Polity, 114 (2006); ver también Jürgen Habermas y William Rehg, Constitutional democracy: A paradoxical union of contradictory principles? 29 Political Theory, n. ${ }^{\circ}$ 6, 766-781 (2001).

[28] Alexander M. Bickel, The morality of consent, Yale University Press, 6-8 (1976); Thomas Irwin Emerson, The system of freedom of expression, Random House, 62-63 (1970)

[29] ARTICLE 19, Los Principios de Camden sobre la libertad de expresión y la igualdad, Global Campaign for free expression, 3 (2009).

[30] Comisión I.D.H., Relatoría Especial para la Libertad de Expresión. Marco jurídico interamericano sobre el derecho a la libertad de expresión. OEA/Ser.L/V/II CIDH/RELE/INF. 2/09, párr. 7 (2009).

[31] Hugo Bustíos Saavedra vs. Perú, Caso 10.548, Comisión I.D.H., Informe n. 38/97, OEA párr. 72 (1997)

[32] Abraham Lincoln, Discurso de Gettysburg, 19 de noviembre de 1863.

[33] Alexander Meiklejohn, Political Freedom, Harper (1960); Robert H. Bork, Neutral principles and some first amendment problems, 47 Indiana Law Journal, n. 1 (1971); Lillian R. BeVier, The First Amendment and Political Speech: An Inquiry into the Substance and Limits of Principle, 30 Stanford Law Review, n. ${ }^{\circ}$ 2, 299 (1978).

[34] Corte Constitucional de Colombia. Sala segunda de revisión. Sala de lo Contencioso Administrativo. Sección Tercera. Sentencia T-391 de 2007. Acción de tutela instaurada por Radio Cadena Nacional S.A. - RCN en contra del Consejo de Estado (M. P. Dr. Manuel José Cepeda Espinosa; 22 de mayo de 2007).

[35] Martin Loughlin, Foundations of public law, Oxford University Press, 353-373 (2010).

[36] Thomas Irwin Emerson, op. cit., 6-7.

[37] Robert C. Post, op. cit., 179-186

[38] Corte Suprema de Canadá. Zundel v. Canada, Comm. HRC 1341/2005, U.N. Doc. A/62/40, Vol. II, at 511 (2007).

[39] Jeremy Waldron, Cap. XI, la participación: el derecho de los derechos, en Derechos y desacuerdos, 277-304 (Ed. Marcial Pons, 2005). 
[40] Andrei Dmitrievich Sakharov, Reflections on Progress, Peaceful Coexistence, and Intellectual Freedom, 22 de Julio de 1968.

[41] Opinión del Juez Brennan.

[42] Suprema Corte de los Estados Unidos, Hustler Magazine and Larry C. Flynt, Petitioners vs. Jerry Falwell, 485 U.S. 46, 108 S. Ct. 876; 99 L. Ed. 2d 41; (1988); Cohen vs. California, 403 U.S. 15 (1971), 91 S. Ct. 1780; 29 L.2d 284; 1971 U.S. LEXIS 32. FCC vs. Pacifica Foundation, 438 U.S. 726 (1978) 8 S. Ct. 3026; 57 L. Ed. 2d 1073; 1978 U.S. LEXIS 135; 43 Rad. Reg. 2d (P \& F) 493; 3 Media L. Rep. 2553.

[43] Supra nota 2.

[44] Drew Gilpin Faust. "Getting Closer": Remarks for the Bicentennial of Harvard Law School. Drew gilpin faust, Sanders theatre, Cambridge, Mass. https://www.harvard.edu/president/speech/2017/getting-closer-remarks-for-bicentennial-harvard-la w-school

[45] Íd

[46] Oliver Wendell Holmes Jr., The path of the law, 10 Harvard Law Review, n. ${ }^{\circ}$ 8, 457 (1897).

[47] Martin Loughlin, The idea of public law, Oxford University Press, 153-163 (2004).

[48] Suprema Corte de los Estados Unidos, Whitney v. California, 274 U.S. 357, 47 S. Ct. 641; 71 L. Ed. 1095, U.S. LEXIS 1011 (1927).

[49] Íd.

[50] Suprema Corte de los Estados Unidos, American Communications Association v. Douds, 339 U.S. 382, 442-43 (1950). 70 S. Ct. 674; 94 L. Ed. 925; U.S. LEXIS 2530; 18 Lab. Cas. (CCH) párr. 65,760; 26 L.R.R.M. 2084 (1950). párr.

[51] Suprema Corte de los Estados Unidos, Chaplinsky vs. New Hampshire, 315 U.S. 56862 S., Ct. 766; 86 L. Ed. 1031; U.S. LEXIS 851 (1942).

[52] Suprema Corte de los Estados Unidos, Terminiello vs. City of Chicago, 337 U.S. 1 (1949), 69 S. Ct. 894; 93 L. Ed. 1131; U.S. LEXIS 2400. (1949).

[53] Suprema Corte de los Estados Unidos, Cohen vs. California, 403 U.S. 15 (1971), 91 S. Ct. 1780; 29 L.2d 284; 1971 U.S. LEXIS 32.

[54] Corte Constitucional de Colombia, Sala novena de revisión. Sentencia T-089 de 2019. Expediente No. T- 6.787.741, Acción de tutela formulada por Hernán Darío Ospina Reyes contra la Universidad Santiago de Cali. (M. P. Alberto Rojas Ríos, 1 marzo de 2019).

[55] Caso Ivcher Bronstein vs. Perú, Sentencia de 6 de febrero de 2001 (Reparaciones y Costas), Comisión I.D.H. Serie C n. ${ }^{\circ}$ 74, párr. 146; Caso "La Última Tentación de Cristo" (Olmedo Bustos y otros) vs. Chile, Sentencia de 5 de febrero de 2001 (Fondo, Reparaciones y Costas). Comisión I.D.H., Serie C n. ${ }^{\circ}$ 73, OEA párr. 64; y La Colegiación Obligatoria de Periodistas (Arts. 13 y 29 Convención Americana sobre Derechos Humanos), Opinión Consultiva OC-5/85, Corte I.D.H. Serie A No. 5, párr. 30 (13 de noviembre de 1985).

[56] Fontevecchia y D'Amico vs. Argentina, Sentencia de 29 de noviembre de 2011, Comisión I.D.H., Series C n. ${ }^{\circ} 238$, párr. 48 y 49 (2011); y el Caso Kimel vs. Argentina, Sentencia 2 de mayo de 2008 (Fondo, reparaciones y costas), Comisión I.D.H., Serie C n. 177 . párr. 51 y 52 (2008).

[57] Pacto Internacional de Derechos Civiles y Políticos, Res. A. G. 2200 A (XXI), O. N. U. Doc. A/RES/2200A(XXI) (1966). Tratado multilateral general que reconoce Derechos civiles y políticos y establece mecanismos para su protección y garantía.

[58] Ricardo Canese vs. Paraguay, Sentencia de 31 de agosto de 2004 (Fondo, Reparaciones y Costas) Comisión I.D.H., Serie C n. ${ }^{\circ}$ 111, OEA párr. 95 (2004); Herrera Ulloa vs. Costa Rica, Sentencia de 2 de julio de 2004 (Excepciones Preliminares, Fondo, Reparaciones y Costas), Comisión I.D.H., Serie C n. ${ }^{\circ}$ 107, OEA párr. 120 (2004); y Palamara Iribarne vs. Chile, Sentencia de 22 de noviembre de 2005 (Fondo, Reparaciones y Costas), Comisión I.D.H., Serie C n. 135 . párr. 79 (2004). 
[59] La expresión "leyes" en el artículo 30 de la Convención Americana sobre Derechos Humanos (Art. 30 n. 22 Corte Interamericana de Derechos Humanos), Opinión Consultiva OC-6/86, Corte I.D.H. (9 de mayo de 1986).

[60] id.; supra nota 53. Caso Kimel vs Argentina.

[61] supra nota 57; supra nota 51 (Caso Kimel vs. Argentina) párr. 84.

[62] Corte Interamericana de Derechos Humanos, artículo 30 de la Convención Americana sobre Derechos Humanos, Supra nota 51 (Caso Fontevecchia) párr. 47 y (Caso Kimel) párr. 84 y 87. Organización de los Estados Americanos (1979).

[63] Caso Ivcher Bronstein vs. Perú, supra nota 53, y el Caso Claude Reyes y otros vs. Chile, Sentencia de 19 de septiembre de 2006 (Fondo, Reparaciones y costas), Corte I.D.H., Serie C n. ${ }^{\circ}$ 151, OEA párr. 87 (2006).

[64] Corte Interamericana de Derechos Humanos, articulo 30 de la Convención Americana sobre Derechos Humanos, supra nota 52, (caso Canese) párr. 83, y (Caso Herrera Ulloa) párr. 113 y 127. Organización de los Estados Americanos (1979).

[65] Caso "La Última Tentación de Cristo" (Olmedo Bustos y otros) vs. Chile, supra nota 53, párr. 152

[66] Kimel vs. Argentina, Sentencia 2 de mayo de 2008 (Fondo, reparaciones y costas), Comisión I.D.H., Serie C n. ${ }^{\circ}$ 177. párr. 93 (2008).

[67] Tribunal Europeo de Derechos Humanos [CEDH]. Lingens v. Austria, fondo y reparación, aplicación n. ${ }^{\circ} 9815 / 82$, asunto n. ${ }^{\circ}$ 12/1984/84/131, A / 103, IHRL 58 (CEDH 1986), [1986] CEDH 7, (1986) 8 EHRR 407, (1986) 8 EHRR 103, (1992) 88 ILR 513, 8 de julio de 1986.

[68] Anne Weber, Manual on hate speech, Council of Europe Publishing, 28-63 (2009).

[69] Eduardo Andrés Bertoni, Libertad de expresión en el Estado de derecho. Doctrina y jurisprudencia nacional, extranjera e internacional, Editores del Puerto, 179 (2007).

[70] Dominic McGoldrick. Though, Expression, Association, and Assembly, en International Human Rights Law 230 (Daniel Moeckli, Sangeeta Shah \& Sandesh Sivakumaran eds., 2014).

[71] John Rawls, A theory of justice, Harvard University Press, 103 (1971)

[72] supra nota 2. También se puede consultar: Stephen L. Newman, Finding the Harm in Hate Speech: An Argument against Censorship, 50 Canadian Journal of Political Science, n. ${ }^{\circ}$ 679-697 (2017). Robert Skipper, Mill and Pornography, 103 Ethics, n. ${ }^{\circ} 4,726-730$ (1993).

[73] Jeremy Waldron, The harm in hate speech, Harvard University Press, 4, 5, 81, 94-95 (2012).

[74] Jeremy Waldron, 2009 Oliver Wendell Holmes Lectures Dignity and Defamation: The Visibility of Hate, Harvard Law School, 1623 (2009).

[75] Brandenburg vs. Ohio, 395 U.S. 444 (more) 89 S. Ct. 1827; 23 L. Ed. 2d 430; 1969 U.S. LEXIS 1367; 48 Ohio Op. 2d 320 (1969).

[76] Whitney vs. California. 274 U.S. 357 (more) 47 S. Ct. 641; 71 L. Ed. 1095; 1927 U.S. LEXIS 1011. (1927)

[77] Íd

[78] Hess Vs. Indiana. 414 U.S. 105 (more) 94 S. Ct. 326; 38 L. Ed. 2d 303; 1973 U.S. LEXIS 177 (1973)

[79] Corte Suprema de Canadá, R. vs. Zundel, 2 S.C.R 21811 (1992).

[80] Ronald Dworkin, Taking rights seriously, op. cit., 21-22.

[81] Íd.

[82] Tamara Relis, op. cit., 519-520.

[83] Denis Galligan and Deborah Sander, op. cit., 23-57.

[84] Antonio Cassese, Human Rights in a Changing World, Temple University Press, 50 (1990). 
[85] Ronald Dworkin, op. cit., 131-134.

[86] Michael Freeman, Universalism of human rights and cultural relativism, en Routledge Handbook of International Human Rights Law (Scott Sheeran \& Sir Nigel Rodley eds., 2013).

[87] John Tilley, Cultural Relativism 22 Human Rights Quarterly, n. 2, $501-547$ (2000).

[88] Sotirios A. Barber \& James E. Fleming, Constitutional interpretation: The basic questions, Oxford University Press, 26-29 (2007).

[89] Richard Lappin, Would External Intervention by Military Force to Protect Civilians in Syria be Legally Justified? 8 Central European Journal of International and Security Studies, n. ${ }^{\circ}$, 137-151 (2014).

[90] Louis Henkin, The Universality of the Concept of Human Rights, 506, The ANNALS of the American Academy of Political and Social Science, $.^{\circ} 1,10,11$ (1989).

[91] Ronald Dworkin, A Matter of Principle, Harvard University Press, 143-145, 165 (1985).

[92] Jonathan I. Charney, Universal International Law, 87 The American Journal of International Law, n. 4, 529-551 (1993).

[93] Rory O'connell, Let's Talk: Dealing with Difference in Human Rights Law, en The Tension Between Group Rights and Human Rights: A Multidisciplinary Approach (Koen De Feyter \& George Pavlakos eds., 2008).

[94] Michael Freeman, supra nota 81.

[95] Sotirios A. Barber \& James E. Fleming, supra nota 82.

[96] “Masacre de Mapiripán” vs. Colombia, Sentencia de 15 septiembre de 2005, Comisión I.D.H., OEA párr. 106 (2005).

[97] Sotirios A. Barber \& James E. Fleming, supra nota 83.

[98] Ronald Dworkin, A Matter of Principle, op. cit., 143-145, 165.

[99] Sotirios A. Barber \& James E. Fleming, op. cit., 26-29 (2007).

[100] Frédéric Mégret, Nature of Obligations, en International Human Rights Law 99-112 (Daniel Moeckli, Sangeeta Shah \& Sandesh Sivakumaran eds., 2014).

[101] James W. Nickel, Making sense of human rights, Ed. Wiley Blackwell, 172 (2007)

[102] Norberto Bobbio, The age of rights, 9-14 (Allan Cameron trans., 1996)

[103] John Tilley, op. cit., 501.

[104] Ronald Dworkin, Freedom's law: The moral reading of the American Constitution, Harvard University Press, 345 (1996).

[105] Beth A. Simmons, Mobilizing for Human Rights: International Law in Domestic Politics, Cambridge University Press, 369-371 (2009).

[106] Sally Engle Merry, Transnational Human Rights, and Local Activism: Mapping the Middle, 108 American Anthropologist, . $^{\circ} 1,38,41$ (2006).

[107] Paul Schiff Berman, A Pluralist Approach to International Law, 32 Yale Journal of International Law, n. ${ }^{\circ}$ 2, $301-311$ (2007).

[108] George Ulrich, Epilogue: widening the perspective on the local relevance of human rights, En The Local Relevance of Human Rights 337-360 (Koen De Feyter, Stephan Parmentier, Christiane Timmerman \& George Ulrich eds., 2011).

[109] Paul Schiff Berman, op. cit., 301, 311.

\section{Licencia Creative Commons CC BY 4.0}

Para citar este artículo/To cite this article: Francisco José Chaux Donado, iNo creo en lo que dicen! Pero defenderé su derecho a decirlo. Una reflexión sobre la importancia constitucional y para los derechos humanos de la libertad de expresión, 68 Vniversitas, n. 139 (2019). https://doi.org/10.11144/ Javeriana.vj139.ncel 